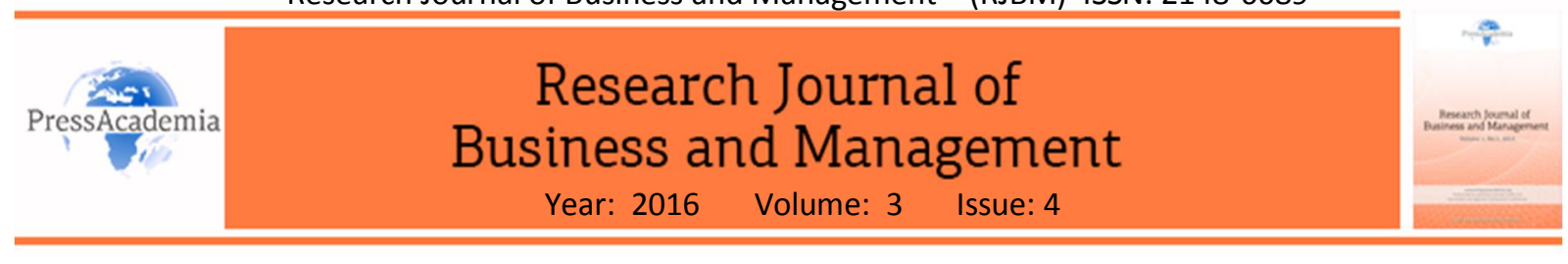

\title{
SATISFACTION MAXIMIZING MODEL FOR MANAGING PROJECT STAKEHOLDERS
}

\section{DOI: 10.17261/Pressacademia.2016.355}

\author{
Chiu-Chi Wei ${ }^{1}$, Chung-Cheng Fu' ${ }^{2}$, Chiou-Shuei Wei ${ }^{3}$ \\ ${ }^{1}$ Chung-Hua University, Taiwan, a0824809@gmail.com \\ 2 Chung-Hua University, Taiwan, mark.c.fu@gmail.com \\ ${ }^{3}$ Lung-Hwa University of Science and Technology, Taiwan, 747964@gmail.com
}

\begin{abstract}
From when a project begins, an uncertain number of stakeholders participate in its planning, execution, monitoring, and controlling, and these stakeholders may change over the course of the project. Project success relies on appropriate stakeholder management and maximization of stakeholder satisfaction. Conventionally, stakeholder management relies solely on the experience and traits of project managers; thus, it can only refer to theories and principles, and cannot be implemented effectively and systematically. To solve this predicament, this study developed a mathematical model that maximizes stakeholder satisfaction considering the level of influence of stakeholders, the available engagement time, project risks, cost of changes, and engagement costs of stakeholders at every stage of a project. The model uses LINGO to calculate the most favorable engagement time for each stakeholder at every stage and maximize stakeholder satisfaction according to the project risk and influence level of stakeholders under conditions of limited engage ment time and cost.
\end{abstract}

Keywords: Project, project management, stakeholder, stakeholder management, stakeholder satisfaction JEL Classification: C61, L84, M12

\section{INTRODUCTION}

Projects are widely implemented in all levels of enterprises, such as the execution of strategies, problem solving, product development, and entering new markets, and function as the main approach of management in nonroutine activities. A project begins with concept development, followed by feasibility analysis, and then enters the stages of planning, execution, controlling, and closing. Stakeholders can have direct or indirect and positive or negative interests in any stage of the project. Depending on the characteristics of projects, stakeholders can be founding members, senior administrators, department managers, suppliers, or customers, all of whom have different levels of importance and influence at various stages of the project. In other words, the varying involvement of stakeholders at different stages of projects directly affects project progression and decision quality. Generally speaking, project managers have two targets: (1) hard target: the project is completed on time and its quality meets stakeholder expectations. (2) soft target: stakeholders' expectations are satisfied during the progression of the project. Even if stakeholders lack sufficient time to participate in a project, the project manager and team members must maximize stakeholder satisfaction, which is a major challenge for project team. The conventional solution has been to arrange and treat stakeholders according to their level of importance. Figure 1 shows a two-dimensional power-interest matrix that provides management strategies for the following parties: stakeholders with high power and interest should be managed closely; parties with low power and high interest should be kept informed; parties with high power and low interest should be kept satisfied; parties with low power and interest should be monitored (PMI, PMBOK, 2015). 
The relationship of stakeholders can be viewed from another perspective. At first, because stakeholders at most only partially understand a project, some may decide they are against it. In some extreme cases, the success of the project could directly affect stakeholders' interests; if stakeholders are not persuaded of the merits of the project, they might reject it altogether. If the project manager and team members successfully execute stakeholder management, stakeholders who were uninformed and resistant at the beginning of the project could become neutral or even supportive and lead other stakeholders to support the project, as Table 1 demonstrates (PMI, PMBOK, 2015). This paper is divided into five sections including introduction, literature review, model development, case implementation and conclusion.

Figure 1: Power-Interest Grid

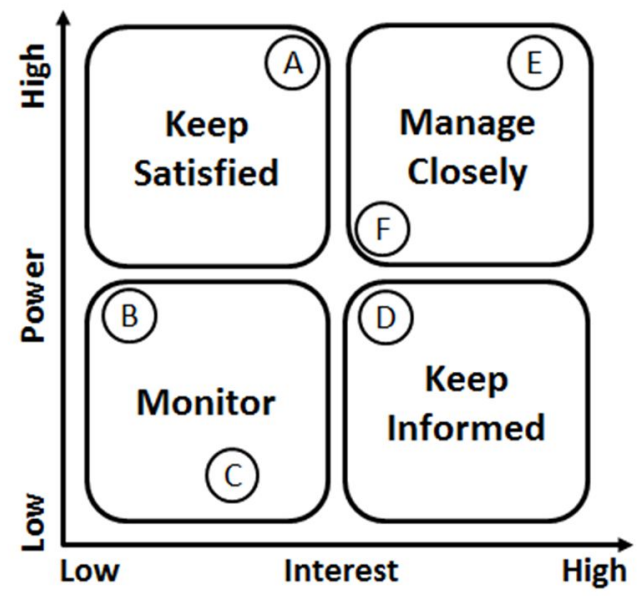

Table 1: Stakeholder Participated Status Assessment

\begin{tabular}{|l|l|l|l|l|l|}
\hline Stakeholder & Unaware & Resistant & Neutral & Supportive & Leading \\
\hline Stakeholder 1 & (C) & & & (D) & \\
\hline Stakeholder 2 & & (C) & & (D) & \\
\hline Stakeholder 3 & & & & (C) (D) & \\
\hline
\end{tabular}

(C): Current (D): Desired

\section{LITERATURE REVIEW}

In stakeholder theory, various stakeholders exist as individuals or groups in a project, and can affect or influence the goals of an organization. Freeman (1984) suggested that stakeholders should agree with the goals of a project; stakeholders must act and communicate differently in accordance with their interests and level of influence. Because the requirement and complexity of a project increases daily, the creation of the establishment of stakeholder management is imperative to creating project value so that project progression corresponds to stakeholder influence (Aapaoja and Haapasalo, 2014). Every stage of the project life cycle involves changes in stakeholders. Project managers should revise the number of key stakeholders, evaluate the level and duration of stakeholders' influence, and manage these stakeholders (Li, 2012). To mediate the project goals and stakeholders' interests, project managers should endeavor to satisfy various stakeholders while executing a project (Jensen, 2002). 
Stakeholders are subjective in their interests (Friedman and Miles, 2006). Stakeholder satisfaction can be managed hierarchically and can be separated into that of internal stakeholders such as employees within the corporation, and that of external stakeholders such as social groups and government organizations (Cleland, 1986). The management hierarchy contains four categories: (1) active stakeholders: decision makers who affect passive stakeholders' decisions; (2) basic stakeholders: stakeholders who work hard to achieve project goals instead of fulfilling personal interests; (3) interest stakeholders: those whose interests are their first priority; (4) power stakeholders: stakeholders who have the power to affect the success of a project (Grimble et al., 1997).

In the egg model described by Urde (1997), the yolk represents the core values and market brand that combines resources and strategies. Half of the egg white is the outside-in demand and influences of external stakeholders, and the other half is the inside-out conditional satisfaction of various stakeholders' demands. Stakeholders have various influences at different stages of a project's life cycle. Project managers should refer to mutual core values when communicating with stakeholders in order to gain positive influence (Gibson 2000). Identifying and analyzing the degree of participation could help project managers understand conflicts of interest and the periodic influence of internal and external stakeholders, which could be monitored and corrected by implementing the plan-do-check-action model in project meetings (Nash and Chinyio, 2010). This allows influences in all stages of the project to remain positive and satisfy the stakeholders.

\section{MODEL DEVELOPMENT}

This section involved the development of a mathematical model for maximizing stakeholder satisfaction. The model considered stakeholders' influence, engagement costs, and engagement time. Generally speaking, stakeholders who are more influential in projects require more time to understand project progression. Second, if certain stakeholders require higher engagement costs, the length of engagement time spent on those stakeholders greatly affects the cost of the project. Lastly, interactions with stakeholders are limited to stakeholders' time. Crucial stakeholders are often busy and of high status, factors that render them less likely to spend extensive time with the project team. In addition, the influence of stakeholders and their engagement time varies according to the progression of the project. Some stakeholders that are influential in the early stages of the project became less influential at the middle stages and even less so in the later stages. Similarly, some stakeholders could be less influential at the beginning, gradually increase their influence at the middle, and exert substantial influence at the end of a project. Detailed data are provided in Table 2 . In Table $2, i_{i j}$ refers to the influence of stakeholder $\mathrm{i}$ at stage $\mathrm{j} ; t_{i j}$ refers to the engagement time of stakeholder $\mathrm{i}$ at stage $\mathrm{j}$; $s_{i j}$ refers to the satisfaction of stakeholder $\mathrm{i}$ at stage $\mathrm{j} ; p r_{j}$ refers to the level of risk at stage $\mathrm{j} ; p c_{j}$ represents costs generated by the changes in stage $j ; i_{j}$ refers to the comprehensive influences of all stakeholders at stage $j$; and index $x_{j}$ refers to the comprehensive importance weight at stage $j$, which was determined on the basis of the risk level of the project, changes in costs, and the influence of stakeholders, and is expressed as index $_{j}=\frac{p r_{j}+p c_{j}+i_{j}}{\max \left(p r_{j}+p c_{j}+i_{j}\right)}$, where $\max \left(p r_{j}+p c_{j}+i_{j}\right)$ is the sum of the three highest values.

Table 2: Maximizing Stakeholder Satisfaction

\begin{tabular}{|c|c|c|c|c|c|}
\hline & \multirow{2}{*}{\multicolumn{2}{|c|}{ Parameter }} & \multicolumn{3}{|c|}{ Project stage j } \\
\hline & & & Stage 1 & Stage 2 & Stage 3 \\
\hline \multirow{5}{*}{$\mathrm{i}$} & \multirow{3}{*}{$P_{1}$} & $i_{1 j}$ & $i_{11}$ & $i_{12}$ & $i_{13}$ \\
\hline & & $t_{1 j}$ & $t_{11}$ & $t_{12}$ & $t_{13}$ \\
\hline & & $s_{1 j}$ & $s_{11}$ & $s_{12}$ & $s_{13}$ \\
\hline & \multirow{2}{*}{$P_{2}$} & $i_{2 j}$ & $i_{21}$ & $i_{22}$ & $i_{23}$ \\
\hline & & $t_{2 j}$ & $t_{21}$ & $t_{22}$ & $t_{23}$ \\
\hline
\end{tabular}




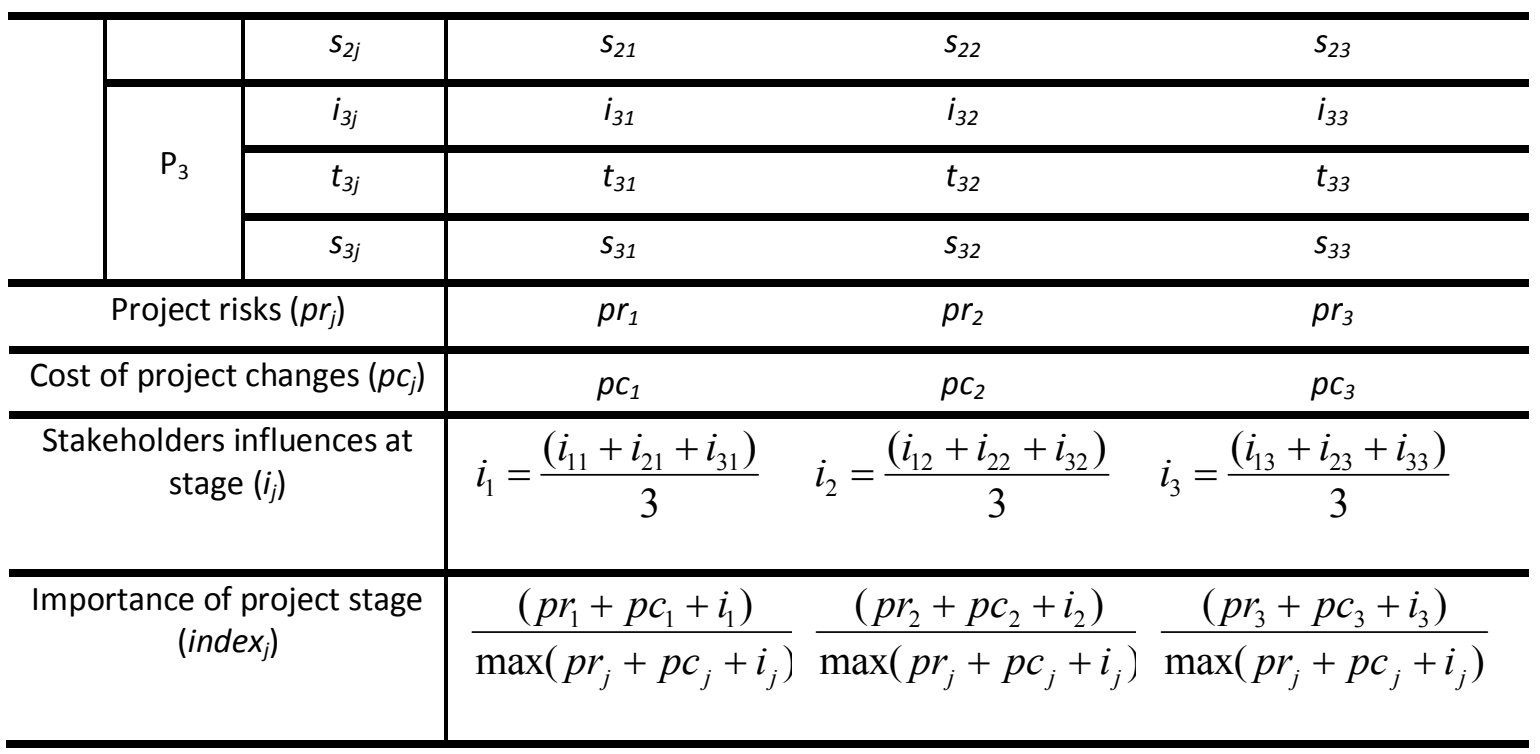

This research proposed a mathematical model for maximizing stakeholder satisfaction that considered the aforementioned factors. The model is expressed as Equation (1):

$$
\operatorname{Max} S=\sum_{i=1}^{m} \sum_{j=1}^{n} i_{i} S_{i j}
$$

S.T. $\quad c_{i}=k_{i} \sum_{j=1}^{n} t_{i j}, \mathrm{i}=1, \ldots, \mathrm{m}$

$$
\begin{aligned}
& \sum_{i=1}^{m} c_{i} \leq C \\
& S_{i j}=f\left(t_{i j}\right) \\
& 0 \leq t_{i j} \leq b_{i j} \\
& t_{i 1}=\frac{\text { index }_{1}}{\text { index }_{2}} t_{i 2} \\
& t_{i 1}=\frac{\text { index }_{1}}{\text { index }_{3}} t_{i 3}
\end{aligned}
$$

where $S$ refers to the total satisfaction of stakeholders,

$k_{i}$ refers to the engagement cost coefficient of stakeholder $i$,

$c_{i}$ refers to the engagement costs of stakeholder $i$,

$C$ refers to the upper limit of all stakeholders' engagement costs,

$b_{i j}$ refers to the upper limit of engagement time of stakeholder $i$ at stage $\mathrm{j}$,

index $_{j}$ refers to the importance of stage $\mathrm{j}$ of the project. 


\section{CASE IMPLEMENTATION}

A case was used to demonstrate the applicability of the model. A project involving three stakeholders, $P_{1}, P_{2}$ and $P_{3}$, was divided into three stages. Stakeholders' influences, the risks of the project, and cost of changes at each stage are listed in Table 3. The influences of stakeholders are illustrated in Table 2, with the importance weight indices at each stage shown in the lowest column.

Table 3: Influence of Stakeholders at Each Project Stage

\begin{tabular}{|c|c|c|c|c|c|}
\hline \multirow{2}{*}{\multicolumn{3}{|c|}{ Parameter }} & \multicolumn{3}{|c|}{ Project stage $\mathrm{j}$} \\
\hline & & & Stage 1 & Stage 2 & Stage 3 \\
\hline \multirow{9}{*}{$\mathrm{i}$} & \multirow{3}{*}{$\mathrm{P}_{1}$} & $i_{1 j}$ & $H(9)$ & $M(5)$ & $\mathrm{L}(1)$ \\
\hline & & $t_{1 j}$ & $t_{11}$ & $t_{12}$ & $t_{13}$ \\
\hline & & $s_{1 j}$ & $s_{11}$ & $s_{12}$ & $s_{13}$ \\
\hline & \multirow{3}{*}{$\mathrm{P}_{2}$} & $i_{2 j}$ & $L(1)$ & $M(5)$ & $H(9)$ \\
\hline & & $t_{2 j}$ & $t_{21}$ & $t_{22}$ & $t_{23}$ \\
\hline & & $s_{2 j}$ & $s_{21}$ & $s_{22}$ & $s_{23}$ \\
\hline & \multirow{3}{*}{$P_{3}$} & $i_{3 j}$ & $\mathrm{~L}(1)$ & $M(5)$ & $M(5)$ \\
\hline & & $t_{3 j}$ & $t_{31}$ & $t_{32}$ & $t_{33}$ \\
\hline & & $s_{3 j}$ & $s_{31}$ & $s_{32}$ & $S_{33}$ \\
\hline \multicolumn{3}{|c|}{ Project risks $\left(p r_{j}\right)$} & $H(9)$ & $M(5)$ & $H(9)$ \\
\hline \multicolumn{3}{|c|}{$\begin{array}{l}\text { Cost of project changes } \\
\qquad\left(p c_{j}\right)\end{array}$} & $\mathrm{L}(1)$ & $M(5)$ & $H(9)$ \\
\hline \multicolumn{3}{|c|}{$\begin{array}{l}\text { Stakeholders influences at } \\
\text { stage }\left(i_{j}\right)\end{array}$} & $\frac{(9+1+1)}{3}=3.7$ & $\frac{(5+5+5)}{3}=5$ & $\frac{(1+9+5)}{3}=5$ \\
\hline \multicolumn{3}{|c|}{$\begin{array}{l}\text { Importance of project } \\
\text { stage (index }{ }_{j} \text { ) }\end{array}$} & $\frac{(9+1+3.7)}{27}=0.6$ & $\frac{(5+5+5)}{27}=0.5$ & $\frac{(9+9+5)}{27}=0.8$ \\
\hline
\end{tabular}

Assume $k_{1}=5, k_{2}=4, k_{3}=3, c=80, s_{i j}=t_{i j}{ }^{2}+t_{i j}+$ constant; $b_{11}=3, b_{12}=2, b_{13}=2, b_{21}=3, b_{22}=2, b_{31}=5, b_{32}=4, b_{33}=3$; and introduce these values into Equation (1). The following Equation (2) was obtained.

$$
\text { Max } \quad 3.7\left(s_{11}+s_{12}+s_{13}\right)+5\left(s_{21}+s_{22}+s_{23}\right)+5\left(s_{31}+s_{32}+s_{33}\right)
$$

$$
\begin{array}{ll}
\text { S.T. } & c_{1}=5\left(t_{11}+t_{12}+t_{13}\right) \\
& c_{2}=4\left(t_{21}+t_{22}+t_{23}\right) \\
& c_{3}=5\left(t_{31}+t_{32}+t_{33}\right) \\
& c_{1}+c_{2}+c_{3} \leqq 80 \\
& s_{11}=t_{11}{ }^{2}+t_{11}+1.5 \\
& s_{12}=t_{12}{ }^{2}+t_{12}+2.3 \\
& s_{13}=t_{13}{ }^{2}+t_{13}+1.9
\end{array}
$$




$$
\begin{aligned}
& s_{21}=t_{21}{ }^{2}-t_{21}+1.2 \\
& s_{22}=t_{22}{ }^{2}-t_{22}+2.5 \\
& s_{23}=t_{23}{ }^{2}-t_{23}+1.6 \\
& s_{31}=t_{31}{ }^{2}+t_{31}+1.4 \\
& s_{32}=t_{32}{ }^{2}+t_{32}+2.2 \\
& s_{33}=t_{33}{ }^{2}+t_{33}+1.1 \\
& 0<t_{11} \leqq 3 \\
& 0<t_{12} \leqq 2 \\
& 0<t_{13} \leqq 2 \\
& 0<t_{21} \leqq 3 \\
& 0<t_{22} \leqq 2 \\
& 0<t_{23} \leqq 2 \\
& 0<t_{31} \leqq 5 \\
& 0<t_{32} \leqq 4 \\
& 0<t_{33} \leqq 3 \\
& t_{11}=(0.5 / 0.6) t_{12} \\
& t_{11}=(0.5 / 0.8) t_{13} \\
& t_{21}=(0.5 / 0.6) t_{22} \\
& t_{21}=(0.5 / 0.8) t_{23} \\
& t_{31}=(0.5 / 0.6) t_{32} \\
& t_{31}=(0.5 / 0.8) t_{33}
\end{aligned}
$$

\begin{tabular}{|c|c|c|c|c|c|}
\hline & \multirow{2}{*}{\multicolumn{2}{|c|}{ Parameter }} & \multicolumn{3}{|c|}{ Project stage $\mathrm{j}$} \\
\hline & & & Stage 1 & Stage 2 & Stage 3 \\
\hline \multirow{6}{*}{$\mathrm{i}$} & \multirow{4}{*}{$P_{1}$} & $i_{1 j}$ & $H(9)$ & $M(5)$ & $\mathrm{L}(1)$ \\
\hline & & $t_{1 j}$ & 1.25 & 1.5 & 2.0 \\
\hline & & $s_{1 j}$ & 4.31 & 6.05 & 7.90 \\
\hline & & $c_{1}$ & & 23.75 & \\
\hline & \multirow{2}{*}{$P_{2}$} & $i_{2 j}$ & $\mathrm{~L}(1)$ & $M(5)$ & $H(9)$ \\
\hline & & $t_{2 j}$ & 1.25 & 1.5 & 2.0 \\
\hline
\end{tabular}

LINGO was used to solve Equation (2), and the maximum value of stakeholder satisfaction was determined to be 256 . The engagement time between project managers and stakeholders and costs and satisfactions at each stage are shown in Table 4.

Table 4: Stakeholder Satisfaction at Different Stages 


\begin{tabular}{|c|c|c|c|c|}
\hline & $s_{2 j}$ & 1.51 & 3.25 & 3.6 \\
\hline & $c_{2}$ & & 19.0 & \\
\hline & $i_{3 j}$ & $\mathrm{~L}(1)$ & $\mathrm{M}(5)$ & $M(5)$ \\
\hline & $t_{3 j}$ & 1.88 & 2.25 & 3.0 \\
\hline 3 & $s_{3 j}$ & 6.79 & 9.51 & 13.1 \\
\hline & $c_{3}$ & & 21.38 & \\
\hline Project & $\overline{\left.p r_{j}\right)}$ & $H(9)$ & $M(5)$ & $\mathrm{H}(9)$ \\
\hline Cost of pro & hanges & $\mathrm{L}(1)$ & $M(5)$ & $H(9)$ \\
\hline $\begin{array}{r}\text { Stakeholde } \\
\text { sta }\end{array}$ & nces at & 3.7 & 5 & 5 \\
\hline $\begin{array}{l}\text { Importan } \\
\text { stage }\end{array}$ & roject & 0.5 & 0.6 & 0.8 \\
\hline
\end{tabular}

Table 3 shows that the engagement time of Stakeholder 1 at Stage 1 was 1.25 with a satisfaction of 4.31; the engagement time at Stage 2 was 1.5 with a satisfaction of 6.05; the engagement time at Stage 3 was 2.0 with a satisfaction of 7.90; and the total engagement cost was 23.75. The engagement time of Stakeholder 2 at Stage 1 was 1.25 with a satisfaction of 1.51; the engagement time at Stage 2 was 1.5 with a satisfaction of 3.25; the engagement time at Stage 3 was 2.0 with a satisfaction of 3.6; and the total engagement cost was 19.0. The engagement time of Stakeholder 3 at Stage 1 was 1.88 with a satisfaction of 6.79 ; the engagement time at Stage 2 was 2.25 with a satisfaction of 9.51; the engagement time at Stage 3 was 3.0 with a satisfaction of 13.1; and the total engagement cost was 21.38 . The index values were $0.5,0.6$, and 0.8 , which indicated that the project was increasing in importance; thus, the engagement time of stakeholders has increased with the progression of the project. Table 3 proves that this occurred. In other words, the model proposed in this study could manage the various characteristics of projects and adjust the engagement time of stakeholders. In addition, when comparing the satisfaction of stakeholders at different stages, the length of the engagement time was not directly related to stakeholder satisfaction. Stakeholders with same length of engagement time were not satisfied equally, a result which matched those observed in actual cases. For example, Stakeholders 1 and 2 demonstrated equal engagement times in all three stages. Satisfaction at Stage 1 was 4.31 for Stakeholder 1 but only 1.51 for Stakeholder 2. Satisfaction at Stage 2 was 6.05 for Stakeholder 1 but only 3.25 for Stakeholder 2, and satisfaction at Stage 3 was 7.90 for Stakeholder 1 but only 3.6 for Stakeholder 2. The engagement costs of the three stakeholders were 23.75, 19.0, and 21.38, respectively, with that of Stakeholder 1 being the highest, followed by those of Stakeholders 3 and 2 . The total satisfaction ratings of the three stakeholders were 18.26, 8.36, and 29.4 respectively, with that of Stakeholder 3 being the highest, followed by those of Stakeholders 1 and 2. When comparing the results of engagement costs and satisfaction measurements, the stakeholder with the highest engagement cost was not necessarily the most satisfied stakeholder. Figure 2 demonstrates the influence, engagement time, and satisfaction of stakeholders at each stage of the project. The white bar refers to level of stakeholder influence, the solid bar refers to stakeholder engagement time, and the slash bar refers to stakeholder satisfaction. 
Figure 2: Comparison of Stakeholders at Different Stages
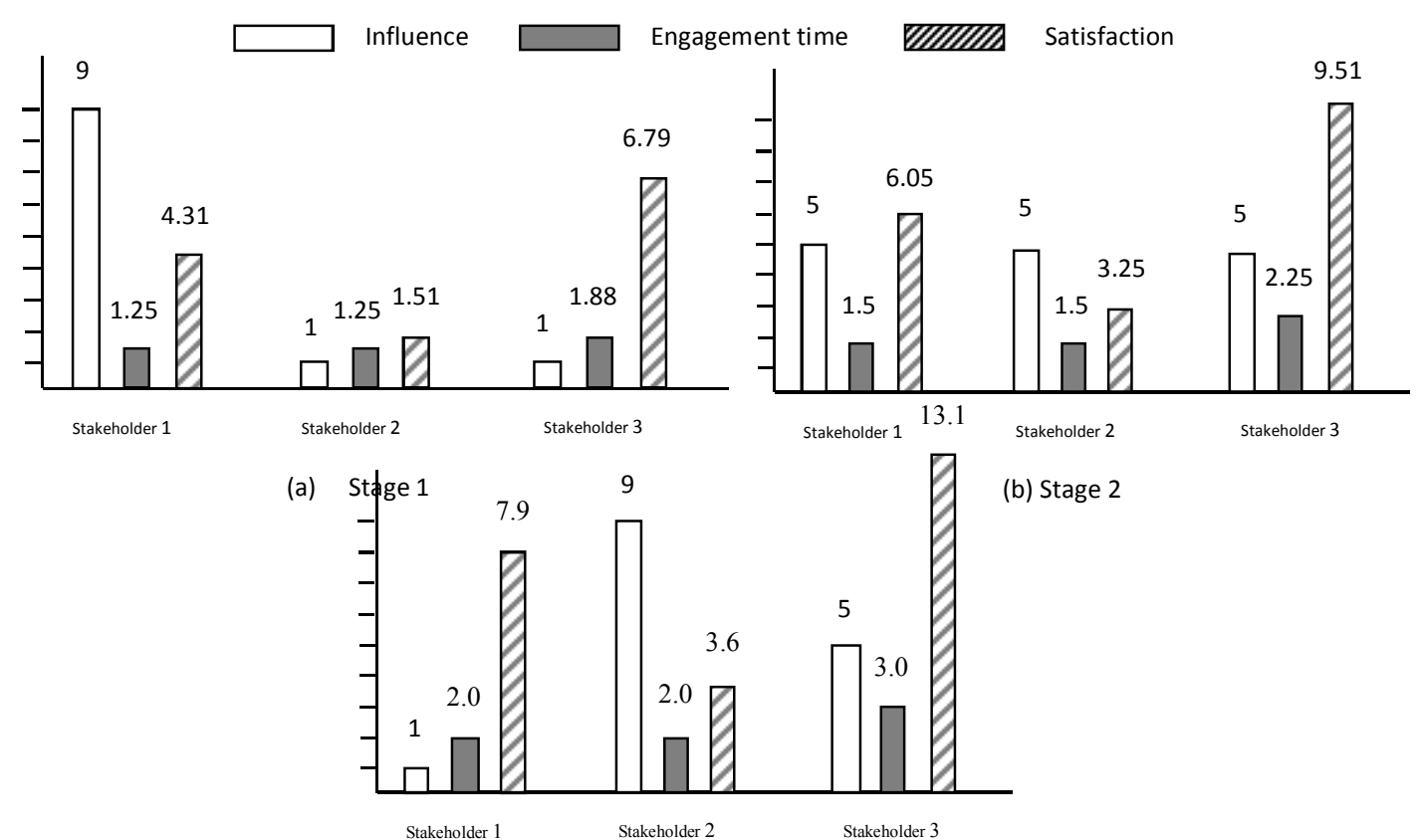

(b) Stage 2

(c) Stage 3

Figure 2(a) clearly shows that Stakeholder 1 was the most crucial stakeholder and had a relatively short engagement time; thus, Stakeholder 1 was rated second in satisfaction. In contrast, Stakeholder 3 was the least crucial stakeholder; however, this stakeholder was rated as having the highest satisfaction, likely because they had the longest engagement time. In Figure 2(b), all three stakeholders had equal influence on the project, but Stakeholder 3 had the longest engagement time and highest satisfaction. Stakeholders 1 and 2 had the same duration of engagement time, but Stakeholder 1 been nearly twice as satisfied as Stakeholder 2 . This could be because the stakeholders' satisfaction corresponded differently to their engagement times; in other words, even if both stakeholders received equal engagement times, their satisfaction would be different. This condition mirrors to real-life circumstances, because different people express different demands and levels of strictness in the same situations. In Figure 2(c), Stakeholder 2 was both the most crucial but least satisfied stakeholder. Stakeholder 1 was the least crucial and received an engagement time equal to that of Stakeholder 2, but Stakeholder 1 was nearly twice as satisfied as Stakeholder 2 . Stakeholder 3 was the most crucial stakeholder at Stage 3 and received the longest engagement time, which could be the reason why they were rated as having the highest satisfaction.

\section{CONCLUSION}

Project management is the most effective approach for enterprises to deal with non-routine activities. Project members are temporarily transferred from different functional departments and a project manager is designated to lead the team in the planning, executing, monitoring, controlling, and completion of project objectives. Whether the project involves product development, market expansion, or organizational reform, project management is an indispensable approach for company management. Enterprises with highly sophisticated project management can shorten the length of time spent on product development, amplify the results of market expansion, facilitate the progress of organizational reform, and create advantages that allow corporations to defeat their opponents. One of the keys to successful project management is to sufficiently manage stakeholders. The conventional approach is to first determine the stakeholders and their demands, and then manage and satisfy these demands. The results of project management depend on the experience and wisdom of the project manager. To improve project managers' performance in stakeholder management, 
this study developed a quantified mathematical model that considered stakeholders' influence, engagement time, project risks, engagement costs, project change costs, and their importance at different stages. The model determined the maximized satisfaction of every stakeholder at different stages of a project. This is one of the few studies to date to have quantified stakeholder management. The case analysis showed that the model assisted project managers in systematically managing stakeholders according to various project conditions. This could allow project managers to improve their performance in stakeholder management, enhance stakeholder satisfaction, and increase the possibility of achieving project objectives.

\section{REFERENCES}

Aaltonen, K. 2011, "Project stakeholder analysis as an environmental interpretation process", International Journal of Project Management, vol. 29, no. 2, pp. 165-183.

Aapaoja, A. \& Haapasalo, H. 2014, "A framework for stakeholder identification and classification in construction projects", Open Journal of Business and Management, vol. 2, pp. 43-55.

Bailey, S. \& Van B. 2015, "Quality of work life issues in the introduction of ERP systems in a sub-saharan african context, ICIME 2015, China.

Chang, K. \& Huang, H. 2003, "Critical factor of WAP services adoption; an empirical study," Electronic Commerce Research and Application, vol. 5, no. 3, pp.25-38.

Cleland, D.I. 1986, "Measuring Success: The owner's viewpoint", Proceedings of the 18th Annual Seminar/Symposium, Montreal, Canada.

Davies A. R. 2013, Right to Buy: The Development of a Conservative Housing Policy, University of Bristol, UK.

Deloitte. 2016, Deloitte and Touche. http://www.stakeholdermap.com/stakeholder-theory.html.

Figueiredo, J. \& Richter, K. 2014, “Advancing the empirical research on lobbying”, Annual Review of Political Science, vol. 17, pp. 163-185.

Freeman, R. E. 1984, Strategic Management: A Stakeholder Approach, Boston, MA.

Friedman A. \& Samantha, M. 2006, Stakeholders: Theory and Practice, Oxford University Press, Oxford, UK.

Garvin, D. 1987, “Competing on the eight Dimensions of Quality", Harvard Business Review, Norvember.

Grimble, R. \& Wellard, K. 1997, "Stakeholder methodologies in natural resource management. A review of principles, contexts, experiences and opportunities", Agricultural Systems, vol. 55, no.2, pp. 173-193.

Jensen, M. 2002, "Value maximization, stakeholder theory, and the corporate objective function", Business Ethics Quarterly, vol. 12, no. 2, pp. 235-256.

Li, G. 2012, “Consumption insurance and local elections: evidence from Chinese villages”, Economics of Transition, vol 20, no. 3, pp. 521547.

Nash S. \& Ezekiel C. 2010, "The Magnitude of Stakeholders' Interests in the Course of Construction Projects", Engineering Project Organizations Conference, South Lake, Tahoe, CA.

Mats, U, Baumgarth, C. \& Merrilees, B. 2013, "Brand orientation and market orientation - From alternatives to synergy", Journal of Business Research, vol. 66, pp. 13-20.

Muller, R. \& Turner, R. 2007, "The influence of project manager on project success criteria and project success by type of project", European Management Journal, vol. 25, no. 4, pp. 298-305.

PMI. 2016, Project Management Body of Knowledge (PMBOK GUIDE), Project Management Institute Inc, PA.

Suchman M. C. 1995, Managing Legitimacy: Strategic and Institutional Approaches. Academy of Management, MI. 